\title{
THE RELATIONSHIP BETWEEN ARM SPAN AND HEIGHT IN ADULT MALES OF NORTH INDIAN PUNJABI POPULATION.
}

Maheshwar Chawla, Rajkumar, Sushma Tomar, Ramkumar Ashoka

1. Assistant Professor, Department of Anatomy, Gold Field Institute of Medical Sciences \& Research, Chhainsa, Ballabgarh, Faridabad, Haryana.

2. Demonstrator, Department of Anatomy, Gold Field Institute of Medical Sciences \& Research, Chhainsa, Ballabgarh, Faridabad, Haryana.

3. Assistant Professor, Department of Anatomy, Gold Field Institute of Medical Sciences \& Research, Chhainsa, Ballabgarh, Faridabad, Haryana.

4. Professor \& HOD, Department of Anatomy, Gold Field Institute of Medical Sciences \& Research, Chhainsa, Ballabgarh, Faridabad, Haryana.

\section{CORRESPONDING AUTHOR}

Dr. Rajkumar (Anatomy Dept.),

Gold Field Institute of Medical Sciences \& Research,

Chhainsa, Ballabgarh, Faridabad-121004 (Haryana).

E-mail: dr.rajkumarghanghas@yahoo.com,

Ph: 00919466833363,00919410066592

ABSTRACT: INTRODUCTION:-Studies have shown that the relationship between Height and arm span varies with age and population ${ }^{11}$. Whether this is true for the North Indian Punjabi male population is not known till date. The measurements of Height and arm span and relationship between them have applied significance in forensic medicine, plastic and cosmetic surgery and other allied clinical sciences. AIMS: - The present study was done with an aim to establish relationship between Height and arm span in adult males of north Indian Punjabi population, as it is not seen in the accessible literature till date to the best of our knowledge.

MATERIALS AND METHOD: Height and arm span of 149 healthy male students between 18 to 25 years of age were measured with the help of an anthropometric rod. The height of all the students were measured in anatomical position keeping all the subjects erect. The height measured was vertical distance from the vertex to floor. Arm span measured was the straight distance between two dactylia from each other, when the arms are fully stretched and are parallel to the floor. All students were free from any kind of physical deformities which can affect Height or arm span. For statistical analysis IBM (Statistical Package for Social Sciences) SPSS + Version 20 was used. RESULT:-The arm span exceeded stature in all the age groups.

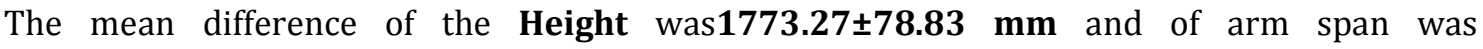
1814.99 $\pm 87.72 \mathrm{~mm}$. This suggests that arm-span measurements may be an inappropriate proxy for height in certain populations. CONCLUSION: The Height and arm span measurements were statistically significant $(\mathbf{p}<\mathbf{0 . 0 5})$. Arm span is a good predictor of stature for males. The correlation between arm span and Height $(\mathbf{r}=0.897 ; \mathbf{p}<0.05)$ was high and significant in all the subjects. This suggests that any future studies attempting to use arm-span measurement as a proxy for height

The findings could also be of practical significance in the field of forensic medicine in case of identification of persons having amputated lower limbs due to accident, or mass disaster.

The present study will also be useful to recognize certain disorders such as Marfan's syndrome and other growth abnormalities. The criteria for exclusion Marfan's syndrome are as follows:- 
1. Arm span greater than height. This means that when your arms are stretched to the side, the distance from finger tip to finger tip is greater than your height.

2. Reduced upper to lower segment ratio. This is when the length of your torso (from shoulders to legs) is shorter than the length of your legs.

3. Curvature of the spine (scoliosis) with a curve greater than 20 degrees.

This work will be of utmost importance for dieticians to assess nutritional requirements.

KEY WORDS: Height, arm span, anthropometric rod, anthropology, dactylion, Punjabi population.

INTRODUCTION: Height of an individual is an inherent characteristic, the estimate of which is important in identification of unknown human remains ${ }^{6}$.

Length of certain long bones and appendages of body represent a certain relationship in the form of proportion to height. Once the skeletal maturity is completed, the proportions do not alter with age. Height has also been calculated from anthropometric measurements of bony fragments, height of spine, face breadth, limb and foot measurements. Body physique, including height and length of long bones are influenced to a great extent by climate, hereditary, nutritional and racial factors ${ }^{2}$. Since in India, variegated ethnic groups inhabit different climate and nutritional \& ecological conditions, no single formula is suitable. Hence different formulae are required for different ethnic groups ${ }^{2}$.

Height is a major indicator of body size and of bone length and it is a composite measurement including head, neck, trunk and extremities.

Relationship between the dimensions of individual body segments and the whole body has been of interest to artists, anthropologists and scientists for many years.

Anthropometric measurements are part of the nutritional assessment which is an important component of health care. Measuring the individual stature with accuracy is very important because it is the basis of estimating basal energy expenditure and consequent nutrient needs and to calculate indices of nutrition. However, common methods of nutritional anthropometric assessment are not entirely satisfactory in elderly person. Height may be difficult to obtain because of postural changes, thinning of intervertebral discs and diminution in the height of the vertebrae with advance ages ${ }^{10}$.

Health care providers often under value the clinical importance of accurate measurement of height. Yet height is a critical variable in the calculation of body surface area (BSA) for drug dosages, vital capacity, basal metabolic rate (BMR), renal clearance and body mass index (BMI). All of these are crucial factors in providing high quality health care to all patients and especially those with serious illnesses. Moreover, height can be difficult or impossible to measure accurately on patients who have conditions such as pain, weakness, compression fracture of vertebrae or paralysis 3 .

The height prediction occupies relatively a central position both in anthropological research and in the identification necessitated by the medical jurisprudence or by medico legal experts. Estimation of height of an individual from the skeletal material or from the mutilated or amputated limbs or parts of limbs has obvious significance in the personal identification in the events of the murders, accidents or natural disasters mainly ${ }^{4}$.

Arm span is the closest physiologic measurement to standing height. Increased arm span to standing height ratio, therefore, indicates possible loss of height, which is a feature of aging, often resulting from osteoporosis-related vertebral collapse. 
All such calculations depend on the fact that the limbs exhibit consistent ratios relative to the total height of person and these ratios are linked to age, sex and race.

MATERIAL AND METHODS: The present study was conducted to establish the relationship of arm span measurement with height in 149 male students of age group 18-25 years of Patiala who were born and brought up in Punjab.

Individual with apparent physical deformities/growth and development defects were excluded.

\section{Apparatus:}

Height and Arm span were measured with anthropometer rod.

Anthropometer Rod (Photograph No.2): It consists of four segments which when joined together form a rigid rod of $200 \mathrm{~cm}$. There is a fixed sleeve on the top of the rod. An adjustable graduated cross bar passes through it. There is also a movable sleeve with an adjustable graduated cross bar, which registers the height measurements.

\section{PROCEDURE:}

Measurement of height (Photograph No.4):- Height is the vertical distance from the vertex to the floor.

During these measurements subject was asked to stand erect barefoot on a level floor against the wall with his back and hip touching the wall. The feet were parallel to each other and heel was touching the wall. The anthropometer rod was kept in the median saggital plane of the subject and the reading was taken at the upper border of movable socket when the point of the cross bar was touching the vertex.

Vertex (Photograph No.1): It is the highest point on head when the head is in eye ear plane.

Bony land marks were marked with a marker and then measurement were taken.

Measurement of arm span (Photograph No.3):- Arm span is the straight distance between two dactylia from each other, when the arms are fully stretched and are parallel to the floor.

Dactylion (Photograph No.1): It is the lowest point on anterior margin of middle finger with arm hanging on the side of the subject. Anterior margin is the tip of the finger (distal margin of the finger).

Anthropometer Rod was held horizontally with zero towards the left. The subject was asked to stand against the wall with his arms fully stretched. Then place the zero point of the rod in such a manner that the tip of the right middle finger touches the zero. Ask the subject to slide the movable socket with middle finger of left hand as far as he can. Then the reading was taken. Reading was taken at the inner border of the movable socket ${ }^{8}$.

\section{Statistical Analysis}

The obtained data were analysed statistically with the help of IBM SPSS VERSION .20 
RESULTS: In present study, upper limb somatometeric data and height of 149 male students of Patiala was collected.

$\mathrm{P}<0.05$ - considered as statistically significant;

The arm span measurement was $1814.99 \pm 87.72 \mathrm{~mm}$, Measurement of height was $1773.27 \pm 78.83 \mathrm{~mm}$.

Regression Equation For Height ( Table No. 2) Height $=44.0912+0.9987$ (AS)

44.0912- constant

0.9987- coefficient

AS - Arm Span

DISCUSSION: The present study was aimed at establishing the relationship of upper limb somatometric measurements with height. It is a study on unbiased mixed homogenous adult male population of Punjab. Though racial and ethnic factors are known to influence the measurements, no such grouping was done in the present study because it is beyond the scope of the present work. This would be of special importance in certain circumstances, such as obtaining height of non ambulatory persons or hand. This would also be used by the anthropologist, equipments designers, ergonomists and dress designers etc.

HEIGHT VS. ARM SPAN: CORRELATION In the present study, coefficient of correlation between height and arm span (measurement in $\mathrm{mm}$ ) is 0.897 (in male of Punjab) (Table 2) while Aggarwal et al in 2000 put the coefficient of correlation as 0.971 in north Indian males ${ }^{1}$. Brown et al (2000) studied in North American males; the coefficient came out to be $0.9^{3}$. Zverev in 2003 conducted study in adult Malawians and deduced the coefficient of correlation as $0.871^{11}$. No such study has been reported in Punjabi Males which throw light on coefficient of correlation between height and arm span. Steel and Mattox in 1987 put the figure to be 0.776 and 0.894 in black and white population respectively of north caolina ${ }^{9}$. Reeves et al in 1990 obtained the coefficient of correlation as 0.73-0.89 in different ethnic groups 7 . Koh et al in 1999 found value of this coefficient of correlation as 0.76 in adult female college students of Korea 5 . The aim of the present study was to obtain a baseline data on adult male population of Punjab. Comparison of COEFFICIENT OF CORRELATION (Table No.4)

Different worker have deduced the regression equation for estimation of height from arm span. Showing in (Table no.4)

No such equation was available for adult Punjabi males. So this study has established the equation to calculate the height from arm span in adult Punjabi males.

The importance of this equation lies in the fact that in some situation the exact height cannot be determined directly due to deformities of lower limb or in patients who have undergone amputation or shortening due to fractures, in these cases if we measure arm span, height can be determined from regression equation. This measured height of patient can be used to calculate their basic energy requirements, standardization of measures of physical capacity and for adjusting drug dosages.

Also, it carries importance in Forensic Science in cases of identification of person whose lower limbs are amputated due to accidents or mass disaster. 
CONCLUSIONS: Correlating and predicting the equations for height from upper limb somatometric measurements, using data from 149 male students of Patiala (aged 18-25 years) of Patiala of Punjabi Origin, was the aim successfully achieved in this study.

The arm span and height was correlated and obtained the coefficient of correlation 0.897 and regression equation has been derived for adult Punjabi males as under:

$H=\mathbf{4 4 . 0 9 1 2}+\mathbf{0 . 9 9 8 7}($ Arm Span)

The mean height $1773.27 \mathrm{~mm}$ and mean of arm span1814.99 $\mathrm{mm}$.

We have used MS Excel 2007 for our calculations and have considered a linear relationship between $X \& Y$ and as such have calculated a linear regression equation of the form $Y=A+B X$.

The linear regression equations derived from arm span for estimation of height showed statistically significant relationship $(p<0.05)$ in Punjabi males.

\section{REFERENCES}

1. Aggarwal AN, Gupta D, Ezekiel LM et al. Statistical estimation of height from arm span in North Indian subjects. Indian J Physiol Pharmacol. 2000;Jul; 44(3):329-34.

2. Bhatnagar DP, Thapar SP, Batish MK. Identification of personal height from the somatometry of the hand in Punjabi males. Forensic Sci Int. 1984 Feb; 24(2):137-41.

3. Brown JK, Feng JY, Knapp TR. Is self-reported height or arm span a more accurate alternative measure of height. Clin Nurs Res. 2002 Nov; 11(4):417-32.

4. Jasuja OP and Singh G. Estimation of stature from hand and phalanges. JIAFM 2004;26(3):0971-3.

5. Koh WJ, Ju YS, Kim TY et al. Arm span-height relationship for prediction of spirometric values in Korean adult women. Tuberc Respir Dis 1999;46(6):784-94.

6. Parikh CK. Identification in mass disasters. In: Parikh's text book of medical jurisprudence and toxicology. $2^{\text {nd }}$ edn. Delihi : CBS Publisher and Distributors; 1998. 6582.

7. Reeves SL, Varakamin C, Henry CJ. The relationship between arm-span measurement and height with special reference to gender and ethnicity. Eur J Cunn Nutr 1996;50(6)398400.

8. Singh IP, Bhasin MK. Instruments In: A laborartory manual on biological anthropology: Anthropometry. $1^{\text {st }}$ ed. Delhi: Kamla-Raj Enterprises; 1968 15-74.

9. Steel MF, Mattox JW. Correlation of arm-span and knee height as proxy indicacators for height.JNDP 2001; 15: 1-5.

10. Tanchoco CC, Duante CA, Lopez ES. Arm span and knee height as proxy indicators for height. JNDP 2001; 15: 1-5.

11. Ter Goon, D., et al the relationship between arm spanand stature in nigerian adults . Kinesiology 43(2011) 1:38-43

12. Zverev YP. Relationship between arm span and stature in Malawian adults. Ann Hum Biol 2003; 30(6):739-43. 


\section{Table 1 SOMATOMETERIC DATA OF ARM SPAN AND HEIGHT}

\begin{tabular}{|c|c|c|c|c|c|}
\hline \multirow{2}{*}{$\begin{array}{l}\text { Study group } \\
\text { (18-25 years) }\end{array}$} & \multirow{2}{*}{$\begin{array}{l}\text { Sample } \\
\text { size (n) }\end{array}$} & \multicolumn{2}{|l|}{ Height (mm) } & \multicolumn{2}{|l|}{ Arm span (mm) } \\
\hline & & Mean \pm SD & Range & Mean \pm SD & Range \\
\hline \begin{tabular}{lcr} 
Male & \multicolumn{2}{c}{ students of } \\
Patiala & of & Punjabi \\
origin. & &
\end{tabular} & 149 & $\begin{array}{ll}1773.27 \quad \pm \\
78.83\end{array}$ & $\begin{array}{l}1640- \\
1950\end{array}$ & $\begin{array}{l}1814.99 \\
87.72\end{array}$ & $\begin{array}{l}1640- \\
1980\end{array}$ \\
\hline
\end{tabular}

Table 2 COEFFICIENT OF CORRELATION ' $r$ '

\begin{tabular}{|l|l|l|}
\hline Parameter & Height & Arm span \\
\hline Height & 1 & 0.897 \\
\hline Arm span & ---- & 1 \\
& & \\
\hline
\end{tabular}

Significant $(\mathrm{p}<0.05)$.

Comparison of COEFFICIENT OF CORRELATION (Table No.3)

\begin{tabular}{|l|l|l|}
\hline $\begin{array}{l}\text { Serial } \\
\text { no. }\end{array}$ & Name of Authors & $\begin{array}{l}\text { COEFFICIENT OF } \\
\text { CORRELATION }\end{array}$ \\
\hline 1. & Present study & 0.897 \\
\hline 2. & Aggarwal et al(2000) & 0.971 \\
\hline 3. & Brown et al(2000) & 0.9 \\
\hline 4. & Zverev et al(2003) & 0.871 \\
\hline
\end{tabular}

Comparison of Regression equation ( Table no.4)

\begin{tabular}{|l|l|l|l|l|}
\hline Serial no. & Name of the Authors & Sample size & Age & Regression equation \\
\hline 1 & Present study & $149($ Male) & $18-25$ yrs & $\mathbf{4 4 . 0 9 1 2 + . 9 9 8 7 ( A S )}$ \\
\hline 2. & $\begin{array}{l}\text { Daniel Ter Goon et } \\
\text { al }\end{array}$ & $180($ Male) & $20-49$ yrs & $\mathbf{6 7 . 6 3 + . 5 7 7 ( A S )}$ \\
\hline 3. & Reeves et al & & & \\
\hline & (a)In Afrocaribbean & $272($ Male) & $23.3(\mathrm{s.d})$ & $\mathbf{6 6 . 9 + 0 . 5 7}($ AS) \\
\hline & (b) In Asian & $272($ Male) & $23.3(\mathrm{s.d})$ & $\mathbf{8 1 . 0 + 0 . 4 8}$ (AS) \\
\hline
\end{tabular}




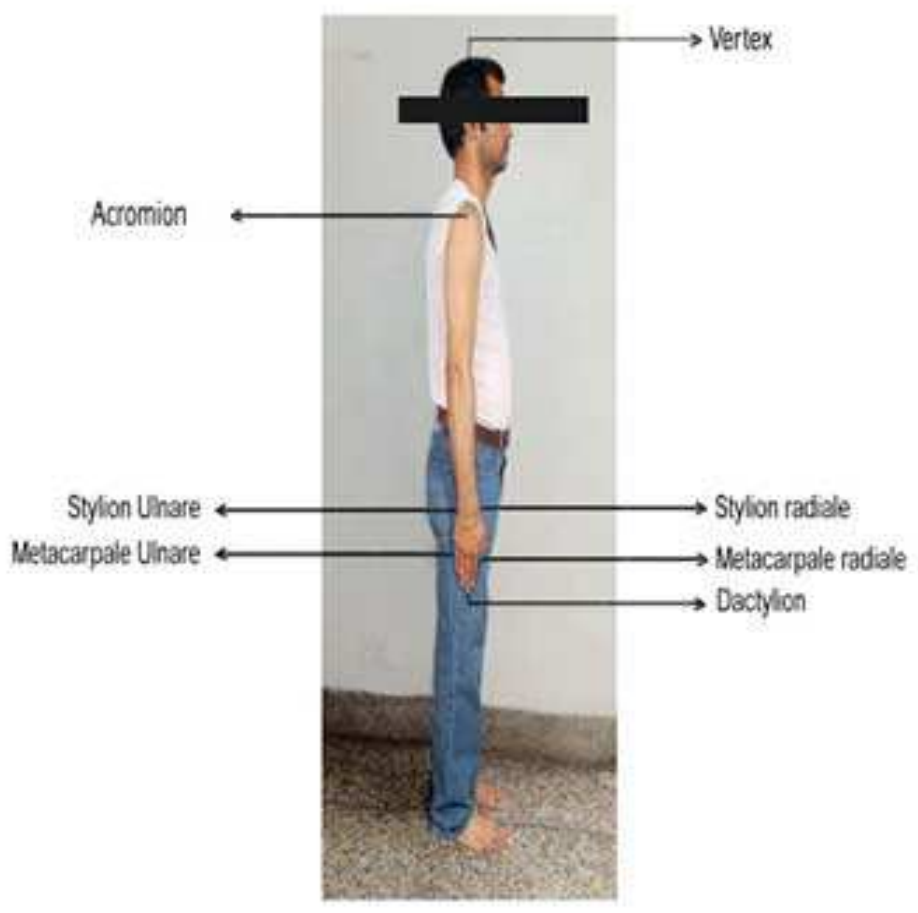

Photograph No.1

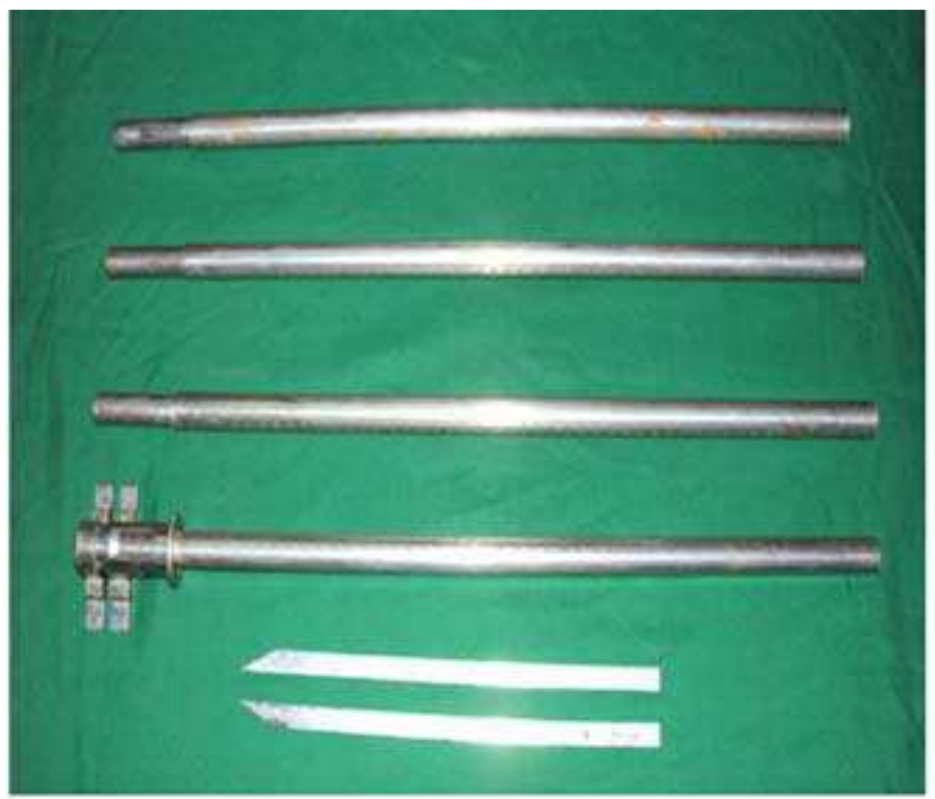

Photograph No.2 (Anthropometer Rod) 


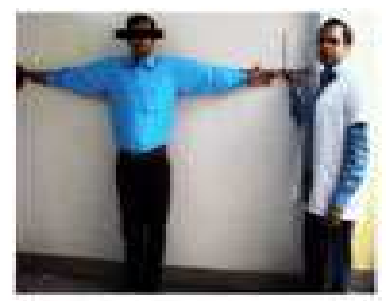

Fhat graphlo. 3 (ARms pan)

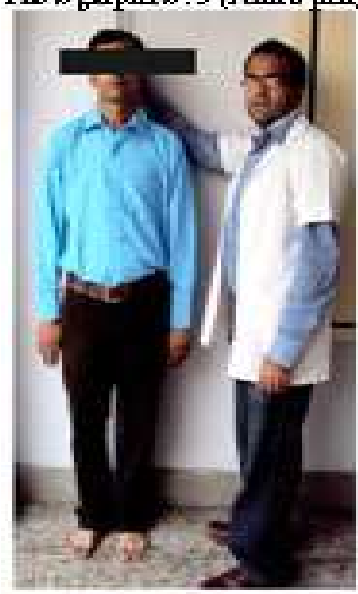

Fhot praphiso.t (5tarwe)

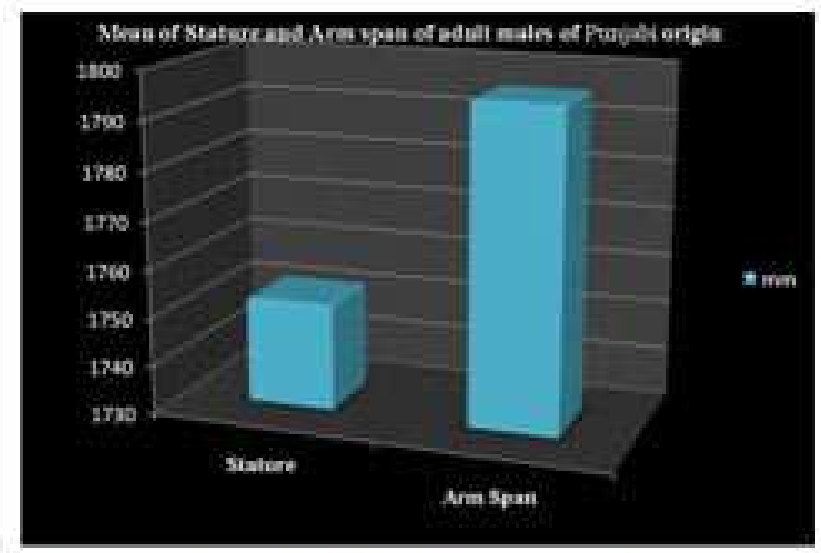

Mean of Height Am span of a dult males of Punjabi origin 